\begin{tabular}{|c|c|c|c|c|c|}
\hline Name. & & Mag. & Colour. & R.A. 1890. & Decl. $\times 890$. \\
\hline $\begin{array}{l}\text { (r) G.C. } 40^{\circ} 7 \\
\text { (2) G.C. } 434 \\
\text { (3) } x \text { Serpentis } \\
\text { (4) } \delta \text { Boötis ... } \\
\text { (5) a Corona } \\
\text { (6) W Cygni }\end{array}$ & $\begin{array}{ll}\ldots & \ldots \\
\ldots & \ldots \\
\ldots & \ldots \\
\ldots & \ldots \\
\ldots & \ldots\end{array}$ & $\begin{array}{c}\bar{z} \\
4 \\
3 \\
2 \\
\text { Var. }\end{array}$ & $\begin{array}{l}\text { White. } \\
\text { Bluish. } \\
\text { Reddish-yellow. } \\
\text { Yellow. } \\
\text { Bluish-white. } \\
\text { Reddish. }\end{array}$ & 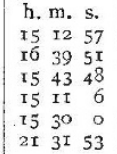 & $\begin{array}{l}+5643 \\
+240 \\
+1829 \\
+3344 \\
+275 \\
+4453\end{array}$ \\
\hline
\end{tabular}

(I) This is a long white nebula in Draco which was described by Sir John Herschel as "a superb ray nebula," The G.C description is: "Considerably bright ; very large ; very much extended in the direction $155^{\circ}$; at first very gradually, then pretty suddenly brighter in the middle, where there is a nucleus." In Herschel's 20 -foot reflector it was seen to be $7 \frac{1^{\prime}}{2}$ long. The spectrum of the nebula has not been recorded.

(2) This is one of the planetary nebulæ, and according to Dr. Huggins its spectrum shows the three bright lines usually seen in nebulæ. He also noted that $\mathrm{F}$ was the faintest line, and that there was a faint continuous spectrum. The spectrum was reobserved by Vogel in 1872 , and he observed two additional lines near wave-lengths $5 \mathrm{I} 8$ and 554 . It is important that these lines should be confirmed, and comparisons made with the flutings of carbon and manganese at 517 and 558 respectively. The existence of these lines will further tend to prove the connection between comets and nebulæe, for two bands in these positions have frequently been observed in cometary spectra. It is not improbable that a third cometary band, near $\lambda 468$, may also appear in the nebula, as a line near that position $(\lambda 470)$ has been recorded by Dr. Copeland and Mr. Taylor in other nebulx. Unfortunately, a rather large aperture is required for this observation; with a ro-inch refractor I have not been able to more than glimpse the additional lines seen by Vogel. The G.C. description of the nebula is: "A planetary nebula; very bright ; very small ; round; disk and border." It is not advisable to employ a cylindrical lens in searching for faint lines, even though the neiula is a small one.

(3) Vogel describes this star as a fine one of Group II., but Dunér states that the bands are narrow, 4 and 5 being little more than lines. He also notes that the spectrum approaches Class II. $a$ (Group III.). It is therefore probable that the spectrum is an intermediate one, and will show some of the lines characteristic of Group III. Any differences in these lines, either in positions or relative intensities, from those seen in stars like the sun, should be noted, as they will form valuable criteria for the subdivision of the Class II.a stars of Vogel into two groups-one of increasing temperatures (Group III.), and the other decreasing (Group V.).

(4 and 5) The first of these has a spectrum of the solar type, and the second one of Group IV. (Gothard). The usual observations are required in each case.

(6) The range of this variable is very small $-5 \cdot 8-6 \cdot 2$ at maximum to $6 \cdot 7-7 \cdot 3$ at minimum-and it will be interesting to observe if any changes in spectrum take place at maximum similar to those which occur in stars of greater range with the same type of spectrum. The general spectrum is a "very fine" one of Group II., but so far no variations with change of magnitude have been noted. The period is given by Gore as $\mathrm{I}_{20-1} 8$ days, and there will be a maximum about June $2 \mathrm{r}$.

The Spectrum of Comet Brooks ( $a$ r 890 ). - - I made further observations of this comet on June 6 and $\%$, and found that it had become considerably brighter since my last observation (NATURE, vol. xlii. p. II2). The tail was also slightly extended. The principal spectroscopic change noted was a diminution in the brightness of the continuous spectrum relatively to the carbon flutings, making the latter more distinct. There was no change in the positions of the bands, and as the comet has now passed perihelion, it is not likely that it will go through any of the higher-temperature stages. As its distance from the sun increases, it should be observed for the cooler stages. The first decided change, according to Mr. Lockyer's investigations, should be the replacing of the present "hot carbon" spectrum for that of "cool carbon," the criterion for which is a fluting near $\lambda 483$. This, again, should be replaced by a spectrum consisting mainly of a line in the position of the chief nebula line $(\lambda 500)$.

In connection with the observations of the comet, I have also made observations of the spectrum of the nebula G.C. $405^{8}$ (see notes for June 5). I found that the spectrum of the nebula NO. IO76, VOL. 42$]$ was irregularly continuous, with a very decided maximum of brightness coincident with the carbon fluting near $\lambda 5 \times 7$. There were also other brightnesses, the positions of which are not yet determined. The whole sfectrum is strikingly similar to that of the comet, and as the two objects are not far removed from each other, this is a good opportunity for observers to satisfy themselves that comets and nebulze are intimately connected.

A. Fowler.

The Planet Uranus.-M. Perrotin, of Nice Observatory, has made some observations of clusky bands on Uranus, similar to those that are seen on Jupiter (Vierteljahrsschrift des Astro. nomische Gesellschaft). The following are some values found for the position-angle :-

$$
\begin{aligned}
& \begin{array}{lllll}
1889 & 3 \mathrm{I} \text { May } & \ldots & \ldots & \mathbf{1} \\
3
\end{array} \\
& \begin{array}{llll}
\text { I June } & \cdots & \cdots & 35 \\
7 & \ldots & 20
\end{array} \\
& 7 \quad, \quad \ldots \quad \ldots \quad 30
\end{aligned}
$$

The mean value is $24^{\circ} .5$, or about $10^{\circ}$ from the plane of the orbit of the satellites, from which it would appear that the plane of the Uranian equator differs little from the trend of the satellites. M. Perrotin also found that the direction of the bands, according to repeated measures, coincided with the longest diameter. The bands do not appear always to have the same aspect, but vary in number and in size in different parts of the surface. This unequal distribution will, it is hoped, afford a means of accurately determining the tine of rotation. The oblateness deduced from the measures is said to be not less than $\frac{1}{25}$.

Mr. TebButt's Observatory. - We have received the Report of this Observatory for the year I880. A considerable amount of extra-meridian work has been done during the year, observations having been made of some minor planets, phenomena of Jupiter's satellites, and uccultations of star; by the moon. Barnard's comet $(a$ 1889) and Davidson's comet (d 1889 ) were observed on eight occasions, and Brooks's comet (e 1889) on two occasions. The comparison observations that were made have been reduced, and sent to Astronomische Nachrichten. Brorsen's periodical comet was carefully searched for, with the help of Dr. Lamp's ephemeris, on December $2 \mathrm{t}$ and 25,1889 , and again on January 18,20 , and 22 , but without success. Comparisons have been made, both of $\eta$ Argûs and $\mathrm{R}$ Carinæe, with the neighbouring stars, and it is noted that the former star has not sensibly varied in its lustre since the announcement of its sudden increase of magnitude between April 1887 and May 1888 . A satisfactory determination of a maximum of the latter star was made in June 1889 , and its period determined as 312 days.

NEW ASTERoID.-A minor planet of the I 3 th magnitude was discovered by M. Charlois at Nice on May zo. This brings the number up to (293).

\section{CORAL REEFS AND OTHER CARBONATE OF LIME FORMATIONS IN MODERN SEAS. ${ }^{1}$}

THE vast organic accumulations known as coral reefs are, undoubtedly, among the most striking phenomena of tropical oceanic waters. The picturesque beauty of coral atolls and barrier reefs, with their shallow placid lagoons, and their wonderful submarine zoological and botanical gardens, fixed at once the attention of the early voyagers into the seas of equatorial regions of the ocean. Qutstions connected with the peculiar form, the structure, the origin, and the distribution of these great natural productions have, from the very outset, puzzlect and interested all those who delight in the study of natural things. In this communication we propose to point out and discuss some of the more general phenomena of oceanic deposits, with special reference to the functions of corals and other lime-secreting organisms, and the accumulation of their dead shells and skeletons on the floor of the great oceans.

Coral reefs are developed in greatest perfection in those ocean waters where the $t \in m$ perature is highest and the annual range is least. It may be said that reefs are never met with where the temperature of the surface water, at any time of the year, sinks below $70^{\circ} \mathrm{F}$, and where the annual range of temperature is greater than $12^{\circ} \mathrm{F}$. Bermuda, which is the coral island the farthest removed from the equator (lat. $32^{\circ} \mathrm{N}$.), and one or two other outlying ree's, may be, in a sense, exceptions to this

- Paper read on December 2, r889, hefore the Royal Society of Edinburgh, by John Murray, LL. I., Ph. D., and Rebert Irvine, F.C.S. 
statement, for in these exceptional cases the temperature of the ocean water appears occasionally to fall to $66^{\circ}$ or $64^{\circ} \mathrm{F}$., and there is a wider annual range than $12^{\circ} \mathrm{F}$. This condition of high temperature with small range in the temperature of the water is only to be met with in the middle and western portion of the Atlantic and Pacific Ocean; and the central parts of the Indian Ocean; consequently, coral reefs flourish along the eastern shores of the continents, where the coasts are bathed by currents of pure oceanic water coming directly from the open sea ; while, on the other hand, they are absent along the western shores of the continents, where the water is colder and the annual range is very much greater - for instance, off the western coast of America and Africa. The Challenger observations have also shown that the layers of warm surface waters are much thicker towards the western parts of the great oceans; consequently, reef-forming organisms flourish at a greater depth along the eastern shores of the continents than in positions further to the eastward in the open ocean, where the warm layer of waterover $70^{\circ} \mathrm{F}$. - is much thinner. Throughout the temperate and polar regions there are no coral reefs. This is all the more remarkable, seeing that organisms belonging to the same orders, families, and cven genera as those which build up coral reefs flourish throughout colder, and even in polar, seas. In these colder seas the representatives of the reef-builders either do not secrete carbonate of lime in their body-walls, or, if they do so, the shells or skeletons are much less massive than in tropical waters. An attentive examination of the animals procured by the dredge and trawl from all depths shows that in descending into deeper water in equatorial regions the amount of carbonate of lime secreted by the animals living on the sea bottom becomes less with increasing depth, and all the calcareous struc tures of the organisms become less massive with the descent into the deeper and colder water of the abysmal regions. This remark does not, of course, apply to the shells and skeletons of surface organisms which have fallen to the bottom from the surface waters.

Still another illustration of the same fact is furnished by the study of the pelagic organisms collected in the surface and subsurface waters by means of the tow-nets. In the warmest tropical waters there are numerous species of Pteropoda, Heteropoda, Gasteropoda, Foraminifera, and Coccospheres and Rhabdosphere (calcareous Algæ), which lead a purely pelagic existence, and secrete carbonate of lime shells. Mr. Murray estimates from his tow-net experiments that at least I 5 tons of carbonate of lime exists in this form at any moment of time in a mass of tropical oceanic water $x$ square mile in extent by 100 fathoms in depth. The number of species and individuals of these lime-secreting organisms decreases and the shells become less massive with a wider removal from the equator and an approach to the colder water of the poles, till we find in the surface waters of the polar regions only one or two thin-shelled Pteropods, and one, or at most two, dwarfed species of pelagic Foraminifera. It would appear then that organisms, as a whole or individually, are able to, and actually do, secrete more lime in regions where there is a uniformly high temperature of the ocean water than in those regions where there are great seasonal fluctuations of temperature, or where there is a uniformly low temperature of the water as in the polar regions and in the deep sea. In temperate seas more carbonate of lime is secreted in the warm summer month than during winter months. Indeed, a high temperature of the sea water is $\mathrm{m}$ rre favourable to abundant secretion of carbonate of lime than high salinity.

An examination of the deep-sea deposits collected by the Challenger and other expeditions in all oceans shows that, after the death of the pelagic organisms above referred to, their calcareous shells are rained down on the ocean's bed, and there make up the larger part of the deposits known as Pteropod and Globigerina oozes, as well as a very considerable part of nearly all other marine deposits. If we take the samples of deep-sea deposits collected by the Challenger as a guide, then the average percentage of carbonate of lime in the whole of the deposits covering the floor of the ocean is 36.83 , and of this carbonate of lime, it is estimated that fully go per cent. is derived from the remains of pelagic organisms that have fallen from the surface waters, the rem inder of the carbonate of lime having been secreted by organisms that live on or attached to the bottom. If coral muds and sands, together with Pteropod and Globigerina oozes, be considered, then it is estimated that these con-

'Murray, "Structure and Origin o? Cozal Reefs," Proc. Roy. Soc. Edin., I880, p. 508 .

NO. IO76, VOL. 42$]$ tain an average percentage of 76.44 of carbonate of lime, and cover about 5I,859,400 square miles of the sea bottom. We have little knowledge as to the thickness of these deposits; still such as we have goes to show that in these organic calcareous oozes and muds, we have a vast formation greatly exceeding in bulk and extent the coral reefs of tropical seas; they are most widely distributed in equatorial regions, but some patches of Globigerina ooze are to be found even within the Arctic circle in the course of the Gulf Stream. The following table shows the estimated area of the various kinds of deposits, with the average depth, and average percentage of carbonate of lime in each :-

Table showing the Estimated Area, Mean Depth, and Mean Percentage of $\mathrm{CaCO}_{3}$ of the different D.posits.

\begin{tabular}{|c|c|c|c|c|}
\hline & Deposits. & $\begin{array}{l}\text { Area, square } \\
\text { miles. }\end{array}$ & $\begin{array}{l}\text { Mean } \\
\text { depth } \\
\text { in } \\
\text { fathoms. }\end{array}$ & $\begin{array}{l}\text { Mean per } \\
\text { cent. of } \\
\mathrm{CaCO}_{3} \text {. }\end{array}$ \\
\hline & Red clay. & $50,289,600$ & 2727 & $6 \cdot 70$ \\
\hline Oceanic & Radiolarian ooze. & $2,790,400$ & 2894 & $4 \% 1$ \\
\hline Oozes and & Diatom ooze. & $10,420,600$ & 1477 & $22 \cdot 96$ \\
\hline Clay. & Globigerina ooze. & $47,752,500$ & 1996 & $64 \cdot 53$ \\
\hline & $\begin{array}{l}\text { Pteropod ooze. } \\
\text { Coral sands and }\end{array}$ & 887,100 & I I I 8 & $79 \cdot 26$ \\
\hline Terrigenous & $\begin{array}{l}\text { muds. } \\
\text {. }\end{array}$ & $3,219,800$ & 710 & $86 \cdot 41$ \\
\hline & $\begin{array}{l}\text { deposits, blue } \\
\text { muds, \&c. }\end{array}$ & $27,899,300$ & 1016 & 19.20 \\
\hline
\end{tabular}

One of the most remarkable facts discovered by the Challenge? Expedition is that, although the dead shells of these pelagic organisms are rained down on the sea bottom, and in shallower depths accumulate so as to form calcareous deposits of immense extent, still, in other contiguous but deeper areas, these shells do not accumulate on the bottom, being wholly removed either while falling through the water, or shortly after reaching the ocean's floor. The pelagic organisms are as abundant in the surface waters over the one area as over the other, the only apparent difference in the conditions being one of depth. In the shallowest deposits of the open sea, shells, representative of nearly all the lime-secreting surface organisms, are to be found in the deposits. W'ith increasing depth the more delicate ones disappear from the bottom, till, in 1800 or 2000 fathoms, it is rare to find more than traces of Heteropod, Pteropod, or the more delicate pelagic Foraminifera shells in the deposits, while these same delicate shells occasionally make up fully one-half of the carbonate of lime that is present in depths of 700 or 1000 fathoms. Again, in the still greater depths of 3000 and 4000 fathoms and deeper, the Foraminifera, Coccoliths, and Rbabdoliths are either wholly removed, or are represented only by the broken fragments of the thickest and most compact shells, like Pulvinulina menardii, Spharoidina dehiscens, or Globirerina conglobata. This gradual decrease in the quantity of carbonate of lime in the deposits with increasing depth is well illustrated in the following table, showing the percentage of lime in the samples of deep-sea deposits collected by the Challenoer towards the central parts of the ocean basins, away from the immediate influence of the débris from continental land or volcanic islands.

The organic oozes, including the red clays and the coral deposits, make up a total of $23 \mathrm{I}$ samples, and are arranged as follows, showing the percentage of carbonate of lime in relation to depth :-

\begin{tabular}{|c|c|c|c|c|}
\hline \multicolumn{5}{|c|}{ cases under 500} \\
\hline & ," & & 500 & 100 \\
\hline 2. & ", & , & 1000 & to 1500 \\
\hline & ," &, & 1500 & to 2000 \\
\hline & ", & , & 2000 & to 2500 \\
\hline & , & $:$ & 2500 & 103000 \\
\hline & ," & ", & 3000 & to 3500 \\
\hline 2 & ," & & 3500 & 104000 \\
\hline & ,, & over & 4000 & \\
\hline
\end{tabular}

\begin{tabular}{|c|c|c|}
\hline $\begin{array}{c}\text { athoms, } \\
\text { ", }\end{array}$ & $\begin{array}{c}\text { m. p.c. } \\
,,\end{array}$ & \\
\hline ", & $"$ & \\
\hline ," & ," & \\
\hline ", & ", & \\
\hline$"$ & ," & \\
\hline , & ," & \\
\hline ", & ", & \\
\hline , & , & \\
\hline
\end{tabular}

The fourteen samples under 500 fathoms are chiefly coral muds and sands, and the seven samples from 500 to 1000 fathoms contain a considerable quantity of mineral particles from continents or volcanic islands. In all the depths greater than 1000 fathoms 
the carbonate of lime is mostly derived from the shells of pelagic organisms that have fallen from the surface waters, and it will be noticed that these wholly disappear from the greater depths. These figure; are derived from a study of the Challenger deposits alone, but they are confirmed, as to the general result, by an examination of the deposits collected by the U.S.SS. Tuscarora and Blake, by H.M.SS. Egeria and Investigator, the ships of the Telegraph Construction and Silvertown Companies, and other ships. One other peculiarity as to the distribution of carbonate of lime organisms on the ocean's floor may be noted. Where these calcareous shells are most abundant on the surface, as in the tropics, the remains of the dead shells are as a rule found at greater depths on the bottom than in temperate or polar regions, where they are relatively much less abundant in the surface waters.

In his paper on the origin of coral reefs, published many years ago, Mr. Murray pointed out that sea-water, rushing in and out of the lagoon twice in the twenty-four hours, would take up and carry away large quantities of the carbonate of lime which, in the form of coral sand and mud, covers the bottom of these shallow basins. Just as the surface shells are dissolved by falling through the layers of ocean water, so in this case the dead cora fragments are dissolved by the sea-water that continually passes over them ; in this way, chiefly, he accounted for the formation of lagoons in atolls and barrier reefs.

During the past few years a large number of experiments have been carried on at the Scottish Marine Station for Scientific Research, with the view of throwing some additional light on the oceanic phenomena referred to in the preceding paragraphs, in so far as these relate to the secretion and solution of carbonate of lime under varying conditions. Those dealing with the secretion of carbonate of lime by organisms will be considered in the first place, and afterwards those treating of the solution of the dead carbonate of lime shells and skeletons will be discussed.

A brief account of some of the experiments will show the nature of the investigations, and indicate the results which have been obtained in so far as they bear on the subject with which we are dealing.

Experiment $\mathbf{r}$. A number of laying hens were shut up in a wooden building, all ordinary sources of lime being withheld. In a few days the eggs, in place of a calcareous shell, had only a membranous covering. Thereafter sulphate, phosphate, nitrate, and silicate of lime were successively added to their otherwise limeless food, and from all these salts they were enabled to form normal shells for their eggs consisting of carbonate of lime.

From the investigations of Irvine and Woodhead it is believed that the lime salts in passing through the blood assume the form of phosphate, which is carried to the point of secretion, where it is decomposed and deposited as carbonate. When magnesium and strontium salts were added to the hens' food the eggs became membranous and shelless.

Ex. 2. Artificial sea-water was prepared, from which carbonate of lime was rigialy excluded. In this water crabs after ecdysis produced the usual exo-skeleton of carbonate of lime from the lime salts, other than carbonate, present in the water.

$E x$. 3. The artificial sea-water of Ex. 2, which was perfectly meutral before the introduction of living crabs, in the course of a short time became distinctly alkaline in character. This was found to be due to the decomposition of their effete nitrogenous products, and the formation of carbonate of ammonia, and ultimately of carbonate of lime.

$E x .4$ and 5. Sea-water was mixed with urine and kept at a temperature ranging from $60^{\circ}$ to $80^{\circ} \mathrm{F}$. After a time the whole of the lime present in the sea-water was thrown down as carbonate and phosphate.

$E x$. 6. A number of small crabs were placed in two litres of ordinary sea-water, and were fed with mussel flesh. This water was not renewed, the effete matters from the crabs passing into it. After a few days the crabs died; the water being then in a putrid condition was set aside at a temperature of fo: $70^{\circ}$ to $80^{\circ} \mathrm{F}$., when it was found that practically the whole calcium in the sea-water had been thrown down as carbonate of lime.

Ex 7. We obtained absolutely fresh "liquor" from a number of living oysters, and examined it before decomposition had begun. It appeared to be a mixture of lymph with unchan yed sea-water. The specific gravity was $\mathrm{r}^{\circ} \mathrm{02} 3$, in ticating a considerable admixture of fresh or river water. This liquor con tained 0.1889 grammes per litre of total lime in excess of that present in sea-water of the same specific gravity, and its No. IO76, VOL. 42 . alkalinity was equal to $0.258 \mathrm{I}$ grammes per litre in excess of sea-water of the same specific gravity.

Thus we had in this liquid an accumulation of total lime (in excess of that present in sea-water) amounting to 0.1889 grammes per litre, the greater part of which was in the form of carbonate in solution, presumably in an amorphous or hydrated condition. Apparently this is due to the direct secretion of carbonate of ammonia by the cells of the living animals, which, reacting on the sulphate of lime in the sea.water, is capable of throwing out nine-tenths of the soluble calcium salts present, in the insoluble condition of carbonate. The oyster liquor was found to contain saline ammoniacal salts in enormous excess over that which is present in ordinary sea-water.

$E x$. 8. A similar experiment was made with the liquor taken from living mussels. The results coincided with those obtained in Ex. 7.

Theoretically urea plus two molecules of water will give carbonate of ammonia. If therefore, this substance be a stage in the formation of urea, it is not unnatural to suppose that in shell-forming animals the shell-formation may take place at this stage without the formation of urea at all. In these experiments the usual method for the estimation of saline and albuminoid ammonia could not be followed, and we made use of the followin $r$ simple adaptation by which we obtained concordant results.

Absolutely pure potash was added to a measured and carefully filtered portion of the sea-water under examination, and the precipitate formed removed by filtration. The clear filtrate was then Nesslerized in the usual manner. We had thus an accurate means of determining between the actual ammoniacal salts and the albuminoid matter, both of which are, as a rule, present in sea-water according to the amount it carries of living and dead organisms. To satisfy ourselves that the addition of pure potash to a fluid containing albuminoids alone does not give rise (immediately) to the production of saline ammonia, we treatect pure albumen taken from a newly laid egg in this manner, as also urea, without obtaining any trace of ammoniacal reaction.

These experiments show the alteration in the constitution of the lime salts in sea-water, both by the decomposition of effete matters thrown into the sea by animals, as also by the secretion of carbonate of ammonia by the cell action of the animals.

Sea-water collected among the coral atolls of the Louisiade Archipelago, received from Captain Wharton, F.R.S., Hydrographer to the Admiralty, contained per million parts-

$\begin{array}{llllll}\text { Saline ammonia } \ldots & \ldots & \ldots & \ldots & \ldots & 0.48 \\ \text { Albuminoid ammonia } & \ldots & \ldots & \ldots & \ldots & 0.18 \\ & & & & & 0.66\end{array}$

whilst water collected by the Challenger in the North Atlantic (lat. $30^{\circ} 20^{\prime} \mathrm{N}$. long. $36^{\circ} 6^{\prime} \mathrm{W}$.) contained-

\section{Saline ammonia}
Albuminoid ammonia

$$
\begin{array}{lllll}
\ldots & \ldots & \ldots & \ldots & 0.26 \\
\ldots & \ldots & \ldots & \ldots & 0.16 \\
& & & & 0.42
\end{array}
$$

and water from the German Ocean near land contained-

$$
\begin{array}{llllll}
\text { Saline ammonia } \ldots & \ldots & \ldots & \ldots & \ldots & 0.13 \\
\text { Albuminoid ammonia } & \ldots & \ldots & \ldots & \ldots & 0.13 \\
& & & & & \overline{0.26}
\end{array}
$$

This is exactly what we were led to expect from the experiments enumerated-the greatest amount of saline ammonia being present where the greatest animal life activity existed, as in the waters from the coral sea; and least in the German Ocean winter water where it was at its minimum.

Thus the whole of the lime salts in sea-water may, under these circumstances, be changed into carbonate, and in this way may be presented to the coral and shell builders in the form suitable for their requirements.

The temperature of the water is of great importance in this reaction. In cold water, of which the great bulk of the ocean consists, the decomposition of nitrogenous organic matter is retarded, whereas in tropical surface waters it proceeds with great rapidity. Thus coral reef builders and pelagic organisms may not only benefit by the decomposition arising from their own effete matter, but also from the undecomposed nitrogenous matter carried to equatorial regions from the cold water of the deep sea, or from polar regions. 
The quantity of carbonate of lime normally present in seawater is exceedingly small ; and the opinion hitherto held seems to have been that lime-secreting organisms must pump enormous quantities of sea-water through their bodies in order to be able to separate out a sufficient quantity to form their shells and skeletons.

Bischoff, in his "Chemical and Physical Geology," vol. i. p. 180, estimates that oysters in this way have to deal with an amount of sea-water equal to from 30,000 to 75,000 times the weight of their shells. It seems more probable that the reactions indicated by our experiments render the whole lime salts in sea-water available for coral polyps to build up their structures. In polyps, which unlike the higher animals have no true circulatory system, and where the animal is immersed in sea-water, it is hardly possible to account for the enormous secretion of carbonate of lime in the manner indicated by Bischoff; but if the conclusion we have arrived at be correct, and such animals, in place of secreting urea, secrete carbonate of ammonia, then we have a perfectly reasonable explanation of the phenomenon of coral formation.

As a laboratory experiment, when carbonate of ammonia is added to sea-water, the greater proportion of the calcium in solution is after a time thrown down as carbonate of lime; whilst the magnesium salts remain in solution. So that if the reaction above indicated be that which takes place in sea-water, then to this circumstance may be due the fact that carbonate of magnesia is almost wholly absent from coral reefs and deep sea ca'careous formations.

That the amount of nitrogenous organic matter in a state of suspension and solution must be enormous will appear evident when it is remembered that the floor of the ocean, almost throughout its whole extent, is covered with living animals; that the surface of the sea and shallow waters off the coasts are crowded with plants and animals down to a depth of several hundred fathoms. (The Challenger experiments have shown that some species of animals flourish in the intermediate depths of ocean water from the surface to the bottom.) The waste products arising from the functional activity of these organisms, and the nitrogenous products arising from the decomposition of their dead bodies, must work continual changes on the internal constitution of sea-water salts, varying according to their amount, the temperature, the sunlight, and other conditions. It has been shown that ammoniacal salts are to be found everywhere in the ocean, but much more abundantly in warm tropical waters than in colder seas - a result no doubt due to the rapid decomposition of the nitrogenous organic matter present at a high temperature, and its retardation in colder water. The ammonia of the air, and all nitrogenous substances carried from the land to the sea, must also effect changes in the internal constitution of seawater. Indeed, the peculiar pelagic fauna and flora met with in all regions of the ocean, where it is affected by river and coast waters, are as different in relation with the internal constitution of the sea-water salts as with the lower salinity which prevails in these circumstances.

It is well known that organic substances in the presence of alkaline and earthy sulphates become oxidized at the expense of the oxygen of these salts, with the production of carbonic and hydrosulphuric acids, the latter on oxidizing producing sulphuric acid. The greater part of the organic carbon, which it has been pointed out is of enormous amount, must apparently be thus oxidized, producing an equivalent amount of carbonic and sulphuric acids. The effects of this reaction are likely to be more marked in the deeper parts of the ocean, where the motion of the sea-water must be extremely slow, and where consequently the effete products accumulate; in this way the larger amount of lime and carbonic acid and the less amount of oxygen in solution in such waters is to be accounted for. Not only so, but the very existence of such a relatively large quantity of sulphate of lime in sea-water goes far to prove that this reaction must continually take place, seeing that sulphuric acid cannot exist in a free state in the presence of carbonate of lime. Thus it is probable that the quantity of sulphate of lime in solution in the ocean is only limited by the amount of organic decomposition which takes place in its waters. On the other hand, if marine organisms procure the whole of their carbonate of lime from the sulphate of lime by the reaction of ammoniacal salts, then the amount of lime that may be secreted from ocean waters is likewise limited by the amount of organic matter undergoing this oxidation process in the ocean.

Gmelin, in his "Chemistry," vol. ii. p. I9I, refers to this decomposition as follows :-

$$
\text { NO. IO76, VOL. 42] }
$$

"In hot climates, as on the west coast of Africa, where the water of rivers charged with organic matter mixes with seawater, hydrosulphuric acid, sometimes to the extent of 6 cubic inches to the gallon, is found in sea-water, even at a distance of 27 miles from the mouth of the rivers."

This is also confirmed from samples of water which we have received, taken from the roadstead of Monte Video by the telegraph ship Seine.

If now we turn our attention to the solution of dead carbonate of lime in shells and coral skeletons by the action of sea-water, it will be found that the rate of this solution varies greatly according to the conditions in which these remains are exposed to the solvent power of the water. A large number of experiments have been conducted with the view of determining the solubility of carbonate of lime under its different conditions. It may be pointed out that the normal amount of carbonate of lime dissolved in sea-water is very small, strikingly so (o' 1200 grammes per litre) when compared with the vast amount of this substance continually being secreted from the sea by organisms. Sea-water can, however, take up 0.6490 grammes per litre of carbonate of lime in an amorphous (or hydrated) condition, forming a clear supersaturated solution, but after a time not only the excess so added is thrown down, but also sometimes a portion of that normally present in the water itself. It would thus appear that it is unable permanently to retain in solution more of this substance than is usually found present in sea-water. This peculiarity o sea-water, after taking up a large amount of amorplious carbonate of lime, and throwing it out in a crystalline form, account for the filling up of the interstices of massive corals with crystal line carbonate in coral islands and other calcareous formations, so that all trace may ultimately be lost of their original organic structure. These experiments show a great diversity as to the amount of carbonate of lime which will pass into solution in seawater from various calcareous structures in a given time. As a rule, the more definitely crystalline the substance is, the less it is soluble. Calcspar is less soluble than massive varieties of coral, and these again less than the more porous varieties. We have already indicated that amorphous or hydrated carbonate of lime is (in that condition) much more soluble than any other form of the substance. The rate of solution is also much greater when the water is constantly renewed, than when the same water remains in contact with carbonate of lime. The water quickly becomes saturated and unable to exert further sclvent action. In this connection we found that different samples of sea-water from different localities possessed very different solvent powers. Especially was this the case between summer and winter waters, the former having distinct solvent action on coral skeletons, whilst with the latter there was hardly any. The lower specific gravity of winter waters may be regarded as to some extent reducing their solvent power, but this is more probably to be attributed to the absence of free carbonic acid-that is, carbonic acid in excess of what is required to saturate the free base in the sea-water as normal carbonate. To test this point, carbonic acid was added to one of these winter waters (which had no solvent action on coral), the quantity added not being sufficient to destroy its alkaline character. It was found that in these circumstances an appreciable amount had been dissolved.

This appears to indicate that there is more carbonic acid in summer than in winter waters in our latitudes, due probably to the increased activity of animal life. Mr. Buchanan's observations on board the Challenger show that the carbonic acid present in sea-water, over and above that necessary to form normal carbonate of lime, was subject to great variations. It appears that this is a much more effective agent in the removal of carbonate of lime shells, \&c., than the solvent power of sea-water itself (although artificial sea-water quitefree from carbonic acid dissolves carbonate of lime). Buchanan's observations have also shown that carbonic acid as a rule is more abundant in bottom than in surface waters; and Reid's experiments show that carbonated sea-waters under high pressure take up more carbonate of lime than that at a normal atmospheric pressure. The fact that carbonic acid is more abundant in deep waters is evidently connected with the respiration, and also the decay, of the animals which live and die on the ocean floor; and also with the decay of those which fall from the surface. The water filling the deeper hollows has also in its passage to the equator passed over thousands of square miles of this floor covered with living animals, and as this water has a very slow motion, and is but slowly renewed, we would expect an accumulation of carbonic acid and deficiency of oxygen in these abysmal depths. When, therefore, carbonate of lime 
secreting animals die at the surface of the water and their bodies fall to the bottom, the shell is exposed to solution from the action of the sea-water through which it passes, and it may be to that of carbonic acid produced by the decomposition of its own organic matter. If the shell be thin, as in the case of Heteropods and Pteropods, it may be wholly removed before reaching the bottom, but the thicker shelled varieties tend to accumulate even in depths of 2000 fathoms, where they are soon covered up by other shells; and being surrounded by sea-water already saturated with carbonate of lime, are preserved from solution, and form vast beds of calcareous ooze. It is found that the amount of carbonate of lime present in such ooze is greater or less according to the depth of water through which the shells pass from the surface to the bottom, and also to the slow renewal of the water in contact with these great lime deposits. In the red clay area the carbonate of lime is almost entirely absent. The deeper waters which cover such areas are more active in the removal of carbonate of lime, not only because of the larger amount of carbonic acid they contain, but doubtless to the deoxidation of alkaline sulphates by organic matter, which, we have already pointed out, gives rise to sulphuric acid, \&c. At the same time account must be taken of the great pressure at such abysmal depths, and the fact that the substance of the shells being less compressible than sea-water, they would fall more slowly, and hence would be longer exposed to the action of the deeper layer of water than those near the surface.

What calcareous remains do reach the ocean floor at such abysmal depths represent the hardest and crystalline varieties of carbonate of lime which resist the solvent action of sea-water to the greatest extent.

In this way we appear to have a perfectly rational explanation of the partial disappearance of carbonate of lime shells from the shallower depths, and their total disappearance from all the greater depths of the ocean. It is to be observed that all those shells in which a considerable quantity of organic tissue is associated with the carbonate of lime disappear in solution more rapidly than the shells of the Foraminifera, which contain little organic matter. (During the whole of the Challenger cruise only two bones of fishes, other than the otoliths and the teeth, were dredged from the deposits, and all traces of the cetacean bones were removed, except the dense ear-bones and dense Ziphioid beaks.) The remains of crustacean animals were almost wholly absent from deep-sea deposits, with the exception of Ostracode shells and the hard tips of some claws of crabs.

Turning now to the lagoons and lagoon channels of coral islands, it is believed that large quantities of carbonate of lime are in the same way being dissolved from these shallow basins as well as from the deposits of the deep sea, but under somewhat different circumstances. In the case of a shell falling to the bottom of the sea, it is continually brought in contact with new layers of water, which has the same effect as if a continuous stream of water were passing over the shell. In the case of the lagoons this last is what takes place. The water which flows in and out of the lagoons twice in twenty-four hours passes over great beds of growing coral, and from all the observations we have is largely charged with carbonic acid, owing probably to the large number of living animals on the outer reef over which the water passes on its way to the lagoon. This water passes continually over the dead coral and sand of the lagoon, and takes up and removes large quantities of carbonate of lime in solution (as well as suspension), for in these lagoons the spaces covered by dead coral débris always greatly exceed the patches of growing coral. Owing to the fact that the water of the lagoon is continually in motion, and constantly renewed, the layer in contact with the bottom of coral sand can never become saturated or unable to take up more lime, as is apparently the case in the layers of water in contact with the Globigerina ooze and other calcareous deep-water cleposits.

From the foregoing discussion and observations it is evident that a very large quantity of carbonate of lime is in a continual state of flux in the ocean ; now existing in the form of shells and corals, but after the death of the animals passing slowly into solution, to go again through the same cycle.

On the whole, however, the quantity of carbonate of lime that is secreted by animals must exceed what is re-dissolved by the action of sea-water, and at the present time there is a vast accumulation of carbonate of lime going on in the ocean. It has been the same in the past, for with a few insignificant exceptions all the carbonate of lime in the geological series of rocks has been secreted from sea-water, and owes its origin to organisms in the same way as the carbon of the carboniferous formations; the extent of these deposits appears to have increased from the earliest down to the present geological period.

At the present time most of the carbonate of lime carried to the ocean by rivers has been directly derived from calcareous stratified rocks formed by organic agency in the sea in earlier geological ages, but the calcium in these formations was in the first instance derived from the decomposition of the lime-bearing silicates of the earth's original crust, and this decomposition, which is still going on in the sea and on the land surfaces, is a continuous additional source of carbonate of lime.

In considering the analyses showing the average composition of sea salts, one is struck with the relatively small quantity of those very substances which are extracted so largely from seawater by plants and animals, viz. carbonate of lime and silica. Siliceous deposits are of vast extent, yet silica occurs merely in traces in sea-water; carbonate of lime deposits are of vastly greater magnitude, yet carbonate of lime makes up only $7^{\frac{1}{9}} \mathrm{t}^{\mathrm{t}} \mathrm{h}$ part of the saline constituents of sea-water, and only $\frac{1}{8300}$ th part of the whole bulk of sea-water. Sulphate of lime is ten times more abundant than the carbonate in sea-water; on the other hand, the river water that is poured into the ocean contains about ten times as much carbonate as it does of sulphate of lime. ${ }^{1}$

The total amount of calcium in a cubic mile of sea-water is estimated from analyses to be 1,941,000 tons, and the total amount of calcium in the whole ocean is calculated at $628,340,000,000,000$ tons. The total amount of calcium in a cubic mile of river water is estimated at I4I,9I7 tons, and the total amount of this element carried into the ocean from all the rivers of the globe annually is estimated at $925,866,500$ tons. At this rate it would take 680,000 years for the river drainage from the land to carry down an amount of calcium equal to that at present existing in solution in the whole ocean. Again, taking the Challenger deposits as a guide, the amount of calcium in these deposits, if they be $\mathbf{2 2}$ feet thick, is equal to the total amount of calcium in solution in the whole ocean at the present time. It follows from this that if the salinily of the ocean has remained the same as at present during the whole of this period, then it has taken about 680 , o00 years for the deposits of the above thickness, or containing calcium in amount equal to that at present in solution in the ocean, to have accumulated on the floor of the ocean. From the data here furnished a number of other interesting speculations might be indulged in, relating to the amount of carbonic acid that has been abstracted from the atmosphere and fixed in carbonate of lime deposits; the total amount of disintegration of lime-bearing siliceous rocks measured in terms of the calcium at present existing in solution in water and fixed in calcareous deposits; the relative proportions of substances secreted from the ocean as compared with other materials derived from the direct disintegration of the land-forming deep-sea deposits and the apparent accumulation of carbonate of lime formations towards the equatorial regions of the globe. These various matters will, however, be discussed in another place.

\section{UNIVERSITY AND EDUCATIONAL} INTELLIGENCE.

CAMBRIDGE. - The event of the week has been the achievement of Miss Philippa Garrett Fawcett, of Newnham College, who, in Part I. of the Mathematical Tripos, is declared to be “ above the Senior Wrangler," Mr. Bennett, of St. John's.

Mr. Sedley Taylor, the delegate from Cambridge to the Sexcentenary Festival of the Montpellier University, in a letter to the Vice-Chancellor on the subject of his mission, writes:"We had the great satisfaction of seeing Prof. von Helmholtz, Delegate of the University of Berlin, publicly received with much cordiality, and of learning that, on account of his optical researches, which have given such a beneficent impulse to modern ophthalmology, he was subsequently made the object of a special ovation by the Medical Faculty for which the University of Montpellier has long been famous."

Dr. Butler, Master of Trinity College, was on June 2 again elected to the office of Vice-Chancellor for the ensuing academical year.

The John Lucas Walker Research Studentship in Pathology is vacant by the resignation of Dr. William Hunter, of St John's College, recently elected to a Research Scholarship in

I Murray, "Total Rainfall of the Globe," Scot. Geogr. Mag., 1887. NO. IO76, VOL. 42] 